\title{
X-Ray Single Crystal Analysis of Oligo(oxymethylene) Diacetates
}

\author{
Koichi Ute, Takehito Takahashi, Ken-ichi Matsui, \\ and Koichi HATADA* \\ Department of Chemistry, Faculty of Engineering Science, \\ Osaka University, Toyonaka, Osaka 560, Japan
}

(Received April 15, 1993)

\begin{abstract}
Individual homologues of oligo(oxymethylene) diacetates, $\mathrm{CH}_{3} \mathrm{CO}_{2}\left(\mathrm{CH}_{2} \mathrm{O}\right)_{n}$ $\mathrm{COCH}_{3}$, from the octamer to the hexadecamer $(8 \leqq n \leqq 16)$ were isolated from a reaction mixture of paraformaldehyde and acetic anhydride by means of preparative supercritical fluid chromatography (SFC). Each oligo(oxymethylene) diacetate showed a sharp endotherm due to melting, and no other phase transition above $-100^{\circ} \mathrm{C}$. Plate crystals were obtained from ethanol solution of the decamer; X-ray crystallographic analysis showed that the crystal is orthorhombic and belongs to the space group $P 22_{1} 2_{1} 2_{1}$. The decamer chain assumes the structure of a $2 / 1$ helix with one-handed screw sense. The packing of the molecules in a unit-cell is of the herringbone type, and the sublattice structure is similar to that of the orthorhombic modification of poly(oxymethylene). The nonamer crystallizes in the monoclinic system of space group $C c$, and the helix pitch of the acetal backbone lies between $9 / 5$ and $2 / 1$. The molecular axis of the nonamer inclines slightly with the lamellar normal ( $a$-axis).
\end{abstract}

KEY WORDS Polyoxymethylene/Oligomer/Supercritical Fluid Chromatography / Chromatography / DSC / Melting Point / X-Ray Single Crystal Analysis / Helix / Conformation / Polymorphism /

Studies on normal alkanes have been useful for analyzing the structure and properties of high molecular weight polyethylene. ${ }^{1,2}$ Similar approaches to the other synthetic polymers would be possible if a series of uniform (monodisperse) oligomers having a sufficiently large degree of polymerization $(D P)$ are available. Recently, much interest has been devoted to chromatographic separation of oligomer mixtures. Particularly, supercritical fluid chromatography (SFC) is one of the most promising techniques for the separation of high $D P$ oligomers, ${ }^{3-8}$ because supercritical mobile phase offers the advantage of high diffusibilities along with widely controllable power of solvation. In the present work, we obtained single crystals of uniform oligo(oxymethylene) diacetates by preparative SFC.

Early attempts to fractionate low molecular

* To whom correspondence should be addressed. weight poly(oxymethylene) were made by Staudinger and his coworkers in the 1920s..$^{9-11}$ The oligo(oxymethylene) diacetates with $1 \leq$ $D P \leq 26$ were isolated by fractional crystallization, and the $D P$ dependence of some physical properties such as melting point and density was investigated. X-Ray diffraction studies (Debye-Scherrer diagrams) of the oligo(oxymethylene) diacetates from the nonamer to the nonadecamer (19 mer) have also been made. These studies provide the basis for the formulation of many concepts essential in macromolecular science.

Poly(oxymethylene) appears in two crystal modifications: the stable trigonal form consisting of 9/5-helix ${ }^{12-14}$ and the metastable orthorhombic form consisting of 2/1-helix. ${ }^{15-17}$ Perfectly uniform oligo(oxymethylene) diacetates are expected to provide good models of 
poly(oxymethylene) crystals.

\section{EXPERIMENTAL}

Oligo(oxymethylene) diacetate was prepared from paraformaldehyde and acetic anhydride according to the procedure described in the literature. ${ }^{9-11}$ A mixture of paraformaldehyde (Sumitomo Seika Chemicals Co., Ltd., 74.6g) and acetic anhydride $(51.1 \mathrm{~g})$ was heated in an autoclave at $160^{\circ} \mathrm{C}$ for $30 \mathrm{~h}$ under a nitrogen atmosphere. The reaction mixture was poured into $200 \mathrm{ml}$ of diethyl ether and the insoluble part $(49.9 \mathrm{~g})$ was filtered off after refluxing for $1 \mathrm{~h}$. The ether solution was washed with aqueous sodium bicarbonate and evaporated. A $44.1 \mathrm{~g}$ portion of the ether-soluble part was subjected to distillation, and the residue (bp $>140^{\circ} \mathrm{C} / 0.08$ Torr, $6.6 \mathrm{~g}$ ) was fractionated by crystallization from diethyl ether solution. By crystallization above $0^{\circ} \mathrm{C}, 0.32 \mathrm{~g}$ of microcrystals was removed. The microcrystals obtained by the crystallization at $0^{\circ} \mathrm{C}(0.55 \mathrm{~g})$ were used for the fractionation with SFC.

SFC was performed on a JASCO SUPER200 chromatograph equipped with a $7.2 \mathrm{~mm}$ i.d. $\times 250 \mathrm{~mm}$ column packed with non-bonded silica gel (JASCO SUPERPAK Crest SIL, particle size $5 \mu \mathrm{m})$. Supercritical $\mathrm{CO}_{2}$ was used as mobile phase (flow rate $=4.5 \mathrm{ml} \mathrm{min}^{-1}$ ), and ethanol was added as entrainer (flow rate $=0.5$ $\mathrm{ml} \mathrm{min}^{-1}$ ). The fluid pressure at the bottom of the column was controlled to $200 \pm 1 \mathrm{~kg} \mathrm{~cm}^{-2}$. The column temperature was adjusted initially to $130^{\circ} \mathrm{C}$, and was lowered at a rate of $2^{\circ} \mathrm{C}$ $\min ^{-1}$ to $40^{\circ} \mathrm{C}$. Chromatograms were recorded using a UV detector JASCO 875-UV operated at a wavelength of $220 \mathrm{~nm}$.

${ }^{1} \mathrm{H}$ NMR spectra were measured in $\mathrm{CDCl}_{3}$ at $35^{\circ} \mathrm{C}$ on a JEOL JNM-GX500 spectrometer. Differential scanning calorimetry (DSC) was performed on a Rigaku DSC-8230 instrument at a heating rate of $5^{\circ} \mathrm{C} \mathrm{min}-1$.

All X-ray data were collected with a Rigaku AFC-5R automated four circle diffractometer using $\mathrm{CuK \alpha}$ radiation $(\lambda=1.5418 \AA, 40 \mathrm{kV}$,
$200 \mathrm{~mA}$ ) in the $\omega$-scan mode. Unit-cell parameters were derived from a least-squares calculation based on 25 (for the nonamer crystal), 20 (for the decamer crystal), or 48 (for the undecamer crystal) intense reflections whose $2 \theta$ angles fell in the range of 55- $60^{\circ}$ (the nonamer), $35-41^{\circ}$ (the decamer), or $51-59^{\circ}$ (the undecamer). Reflection data were empirically corrected for absorption by the method of North et al. ${ }^{18}$ Numerical corrections for damage by $\mathrm{X}$-ray radiation were also made. Three standard reflections monitored every 100 reflections decayed by $1.2-1.5 \%$ (in $\left|F_{o}\right|$ ) during data collection. Crystal structures were solved by the direct method (SHELXS ${ }^{19}$ ). The structure of the nonamer was refined by the full-matrix least-squares procedure with anisotropic thermal parameters for all nonhydrogen atoms. For the decamer, positions of oxygen atoms were refined anisotropically and those of carbon atoms isotropically. Hydrogen atoms were not included in the refinements because of shortage of observed reflections. The lattice dimensions for the undecamer crystal were confirmed by Weissenberg photographs.

\section{RESULTS AND DISCUSSION}

Figure 1a shows an SFC curve of the oligo(oxymethylene) diacetate obtained by the fractional crystallization from diethyl ether

(b)

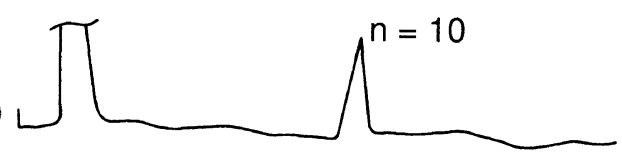

(a)

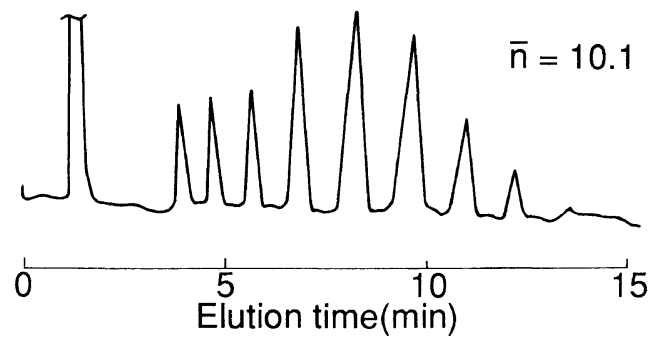

Figure 1. SFC curves of oligo(oxymethylene) diacetate (a) and the decamer isolated by SFC-fractionation (b). 


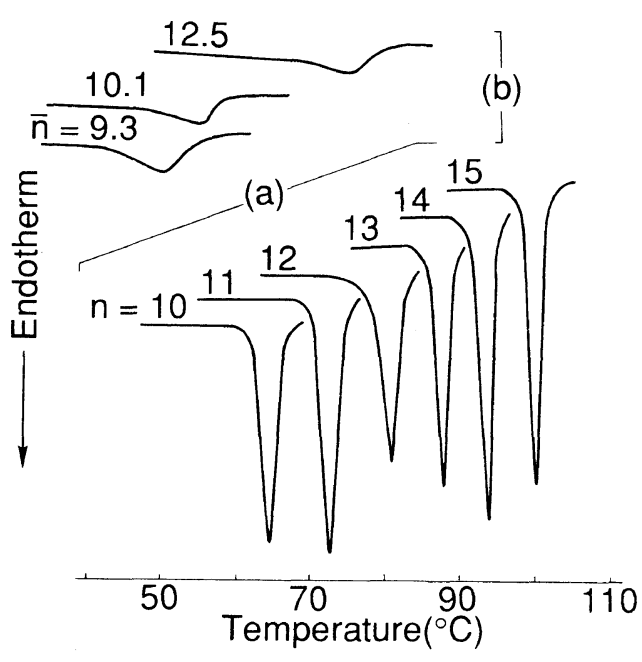

Figure 2. DSC curves of the uniform oligo(oxymethylene) diacetates from the decamer to pentadecamer (a) and oligo(oxymethylene) diacetates obtained by fractional crystallization (b).

solution at $0^{\circ} \mathrm{C}$. The fraction consisted of the oligomers from the hexamer to the tetradecamer. Individual oligomers were isolated by repeated fractionation with the SFC, and purified by crystallization from ethanol. Reinjection of the oligomer crystals to the SFC proved their purities; a representative chromatogram is shown in Figure $1 \mathrm{~b}$. The $D P$ of the oligomers was determined from an intensity ratio of the ${ }^{1} \mathrm{H}$ NMR signals due to the methylene protons and the acetyl end-groups. The value agreed well with the $D P$ measured by potassium ionization mass spectrometry of desorped species. ${ }^{20}$

Each oligomer showed a sharp endotherm due to melting and no other phase transition above $-100^{\circ} \mathrm{C}$ (Figure 2a). The sharpness of the melting endotherms of the oligomers compares favorably with that of the oligo(oxymethylene) diacetates reported in the past. $^{21}$ The oligo(oxymethylene) diacetate samples obtained by fractional crystallization exhibited broader melting endotherms (Figure $2 b$ ), and the melting points were lower than those of the uniform oligomers with the equivalent $D P$. The melting points for the
Table I. Crystallographic data on oligo(oxymethylene) diacetates ${ }^{\mathbf{a}}$

\begin{tabular}{|c|c|c|c|}
\hline & 9 mer & $10 \mathrm{mer}$ & $11 \mathrm{mer}$ \\
\hline Formula & $\mathrm{C}_{13} \mathrm{H}_{24} \mathrm{O}_{12}$ & $\mathrm{C}_{14} \mathrm{H}_{26} \mathrm{O}_{13}$ & $\mathrm{C}_{15} \mathrm{H}_{28} \mathrm{O}_{14}$ \\
\hline $\begin{array}{r}\text { Formula } \\
\text { weight }\end{array}$ & 372.33 & 402.35 & 432.38 \\
\hline $\begin{array}{l}\text { Crystal } \\
\text { system }\end{array}$ & monoclinic & orthorhombic & monoclinic \\
\hline Space group & $\mathrm{Cc}$ & $P 2_{1} 2_{1} 2_{1}$ & $C 2$ \\
\hline$a / \AA$ & $46.360(3)$ & $7.610(1)$ & $114.56(1)$ \\
\hline$b / \AA$ & $5.0538(5)$ & $42.244(7)$ & $9.080(2)$ \\
\hline$c / \AA$ & $7.7366(8)$ & $5.959(1)$ & $7.838(2)$ \\
\hline$\beta / \operatorname{deg}$ & $91.061(1)$ & 90.000 & $90.19(1)$ \\
\hline$V / \AA^{3}$ & $1812.3(3)$ & $1915.7(6)$ & $8153(2)$ \\
\hline Z & 4 & 4 & 16 \\
\hline$D_{\text {calcd }} / \mathrm{g} \mathrm{cm}^{-3}$ & 1.364 & 1.395 & 1.409 \\
\hline $\begin{array}{l}\text { Measured } \\
\text { reflections }\end{array}$ & 1451 & 1826 & 6957 \\
\hline $\begin{array}{l}\text { Observed } \\
\text { reflections }\end{array}$ & $1157[4 \sigma]$ & $1670[5 \sigma]$ & - \\
\hline $\begin{array}{l}\text { Number of } \\
\text { parameters }\end{array}$ & 159 & 244 & - \\
\hline$R_{/}^{\mathrm{b} / \%}$ & 10.30 & 9.11 & - \\
\hline$R_{w}{ }^{\mathrm{c}} / \%$ & 12.55 & 12.04 & - \\
\hline
\end{tabular}

a Estimated standard deviations in the least significant digit are given in parentheses.

b $R=\Sigma|| F_{o}|-| F_{c}|| / \Sigma\left|F_{o}\right|$.

c $R_{w}=\left[\sum w\left(\left|F_{o}\right|-\left|F_{c}\right|\right)^{2} / \sum w\left|F_{o}\right|^{2}\right]^{1 / 2} ; w=1 / \sigma^{2}\left(F_{o}\right)$.

decamer, undecamer, and dodecamer as determined by DSC were $63.1-66.2^{\circ} \mathrm{C} 71.2$ $73.7^{\circ} \mathrm{C}$, and $79.9-82.5^{\circ} \mathrm{C}$, respectively. A comparison of the melting points for our oligomers with the data in the literature $\left(52-53.5^{\circ} \mathrm{C}\right.$ for the decamer, $64-65^{\circ} \mathrm{C}$ for the undecamer, and $73-75^{\circ} \mathrm{C}$ for the dodecamer $)^{9-11}$ indicated a clear improvement in purity in our materials.

Single crystals of each oligomer were grown from ethanol solutions. The crystallographic details are given in Table I. The calculated density $\left(D_{\text {calcd }}\right)$ of the oligomers increased with $D P ; D_{\text {calcd }}$ of the dodecamer $(12 \mathrm{mer})$ was $1.411 \mathrm{~g} \mathrm{~cm}^{-3}$ as determined by X-ray crystallographic analysis. The values were almost comparable with the experimentally found density of poly(oxymethylene) (1.40-1.45 $\left.\mathrm{g} \mathrm{cm}^{-3}\right){ }^{22}$ The fractional atomic coordinates 
Table II. Fractional atomic coordinates for deca(oxymethylene) diacetate ${ }^{a}$

\begin{tabular}{|c|c|c|c|}
\hline Atom & $X / a$ & $Y / b$ & $Z / c$ \\
\hline $\mathrm{O} 1$ & $0.8960(8)$ & $0.4298(1)$ & $-0.3597(11)$ \\
\hline $\mathrm{O} 2$ & $0.7584(6)$ & $0.4152(1)$ & $-0.0511(8)$ \\
\hline $\mathrm{O} 3$ & $0.9410(5)$ & $0.3717(1)$ & $0.0033(8)$ \\
\hline $\mathrm{O} 4$ & $0.7996(6)$ & $0.3521(1)$ & $0.3230(8)$ \\
\hline O5 & $0.9522(5)$ & $0.3038(1)$ & $0.3587(8)$ \\
\hline O6 & $0.8068(5)$ & $0.2851(1)$ & $0.6780(8)$ \\
\hline O7 & $0.9461(6)$ & $0.2362(1)$ & $0.7127(8)$ \\
\hline O8 & $0.7973(6)$ & $0.2171(1)$ & $1.0302(8)$ \\
\hline O9 & $0.9428(5)$ & $0.1687(1)$ & $1.0735(8)$ \\
\hline $\mathrm{O} 10$ & $0.7953(6)$ & $0.1477(1)$ & $1.3808(8)$ \\
\hline O11 & $0.9489(5)$ & $0.0993(1)$ & $1.3970(9)$ \\
\hline $\mathrm{O} 12$ & $0.8109(7)$ & $0.0804(1)$ & $1.7143(9)$ \\
\hline $\mathrm{O} 13$ & $0.9379(9)$ & $0.0342(1)$ & $1.6402(16)$ \\
\hline $\mathrm{Cl}$ & $0.7389(12)$ & $0.4692(2)$ & $-0.1433(19)$ \\
\hline $\mathrm{C} 2$ & $0.8080(10)$ & $0.4363(2)$ & $-0.1979(14)$ \\
\hline $\mathrm{C} 3$ & $0.7850(8)$ & $0.3828(1)$ & $-0.0978(13)$ \\
\hline $\mathrm{C} 4$ & $0.9422(9)$ & $0.3708(1)$ & $0.2398(12)$ \\
\hline $\mathrm{C} 5$ & $0.8085(9)$ & $0.3201(1)$ & $0.2628(12)$ \\
\hline C6 & $0.9504(9)$ & $0.3027(1)$ & $0.5943(12)$ \\
\hline $\mathrm{C} 7$ & $0.8037(9)$ & $0.2531(1)$ & $0.6170(12)$ \\
\hline $\mathrm{C} 8$ & $0.9454(8)$ & $0.2345(1)$ & $0.9522(12)$ \\
\hline C9 & $0.7987(8)$ & $0.1850(1)$ & $0.9720(12)$ \\
\hline $\mathrm{C} 10$ & $0.9338(9)$ & $0.1666(2)$ & $1.3095(12)$ \\
\hline $\mathrm{C} 11$ & $0.8016(9)$ & $0.1158(2)$ & $1.3106(13)$ \\
\hline $\mathrm{C} 12$ & $0.9588(9)$ & $0.0973(2)$ & $1.6331(14)$ \\
\hline $\mathrm{C} 13$ & $0.8140(12)$ & $0.0492(2)$ & $1.7098(17)$ \\
\hline $\mathrm{C} 14$ & $0.6422(16)$ & $0.0352(3)$ & $1.8053(31)$ \\
\hline
\end{tabular}

a Estimated standard deviations in the least significant digits are given in parentheses.

for the decamer and nonamer appear in Tables II and III.

The crystals of the decamer were obtained in the form of oblong plates. The $b$ axis is normal to the plate, and the $c$ and $a$ axes are parallel to the longer and shorter sides, respectively. Figure 3 shows the crystal structure of the decamer. The packing of molecules in a unit-cell was of a herringbone type, i.e., the double-layered polytype stacking of molecular layers in which the molecules are inclined by $35^{\circ}$ to the lamellar surface and inclination direction rotates by $180^{\circ}$ in the neighboring layer. The unit-cell consists of four molecules with the $2 / 1$ helix conformation. The crystal symmetry $\left(P 22_{1} 2_{1}\right)$ leads to a remark-
Table III. Fractional atomic coordinates for ona(oxymethylene) diacetate ${ }^{a}$

\begin{tabular}{|c|c|c|c|}
\hline Atom & $X / a$ & $Y / b$ & $Z / c$ \\
\hline $\mathrm{Ol}$ & $-0.1227(1)$ & $0.3718(15)$ & $0.1406(11)$ \\
\hline $\mathrm{O} 2$ & $-0.1007(1)$ & $0.1478(16)$ & $0.3593(10)$ \\
\hline $\mathrm{O} 3$ & $-0.0581(1)$ & $0.3281(16)$ & $0.2402(9)$ \\
\hline $\mathrm{O} 4$ & $-0.0193(2)$ & $0.1959(20)$ & $0.4160(10)$ \\
\hline O5 & $0.0216(1)$ & $0.2827(19)$ & $0.2433(10)$ \\
\hline O6 & $0.0611(1)$ & $0.2372(20)$ & $0.4372(9)$ \\
\hline $\mathrm{O} 7$ & $0.1010(1)$ & $0.2446(17)$ & $0.2577(10)$ \\
\hline O8 & $0.1405(2)$ & $0.2731(18)$ & $0.4422(9)$ \\
\hline O9 & $0.1805(1)$ & $0.2034(18)$ & $0.2802(9)$ \\
\hline $\mathrm{O} 10$ & $0.2201(2)$ & $0.3149(19)$ & $0.4509(11)$ \\
\hline O11 & $0.2619(1)$ & $0.1696(16)$ & $0.3302(10)$ \\
\hline $\mathrm{O} 12$ & $0.2865(2)$ & $0.3709(17)$ & $0.5483(12)$ \\
\hline $\mathrm{Cl}$ & $-0.1428(2)$ & $-0.0315(25)$ & $0.2327(16)$ \\
\hline $\mathrm{C} 2$ & $-0.1217(2)$ & $0.1794(19)$ & $0.2440(12)$ \\
\hline $\mathrm{C} 3$ & $-0.0786(2)$ & $0.3415(23)$ & $0.3812(15)$ \\
\hline $\mathrm{C} 4$ & $-0.0389(2)$ & $0.1321(21)$ & $0.2802(14)$ \\
\hline $\mathrm{C} 5$ & $0.0011(2)$ & $0.3756(23)$ & $0.3620(15)$ \\
\hline C6 & $0.0414(2)$ & $0.1148(22)$ & $0.3266(13)$ \\
\hline $\mathrm{C} 7$ & $0.0811^{\mathrm{b}}$ & $0.4006(18)$ & $0.3428^{\mathrm{b}}$ \\
\hline $\mathrm{C} 8$ & $0.1215(2)$ & $0.0849(29)$ & $0.3639(16)$ \\
\hline $\mathrm{C} 9$ & $0.1615(3)$ & $0.4087(26)$ & $0.3337(16)$ \\
\hline $\mathrm{C} 10$ & $0.2010(3)$ & $0.1011(28)$ & $0.4108(19)$ \\
\hline $\mathrm{C} 11$ & $0.2427(2)$ & $0.3935(22)$ & $0.3327(15)$ \\
\hline $\mathrm{C} 12$ & $0.2853(2)$ & $0.2074(25)$ & $0.4579(16)$ \\
\hline $\mathrm{C} 13$ & $0.3065(2)$ & $-0.0340(26)$ & $0.4332(16)$ \\
\hline
\end{tabular}

a Estimated standard deviations in the least significant digits are given in parentheses.

b The parameters were fixed to define the floating origin in the space group $(C c)$.

able structural conclusion that the lattice must be made up of one-handed helices. The torsional angles for the acetal backbone are given in Table IV. It is interesting to note that the sublattice structure of the decamer crystal ( $c f$. Figure 4a) is very similar to that of the orthorhombic modification of poly(oxymethylene). ${ }^{15}$ These structural features of the decamer crystal have made possible comprehensive analysis of the vibrational assignments for the micron-sized orthorhombic poly(oxymethylene) single crystals on the basis of polarized infrared and Raman spectroscopies. ${ }^{23}$

The nonamer crystallized in the monoclinic system of space group $C c$. Four molecules are packed in a unit-cell with their molecular axes 


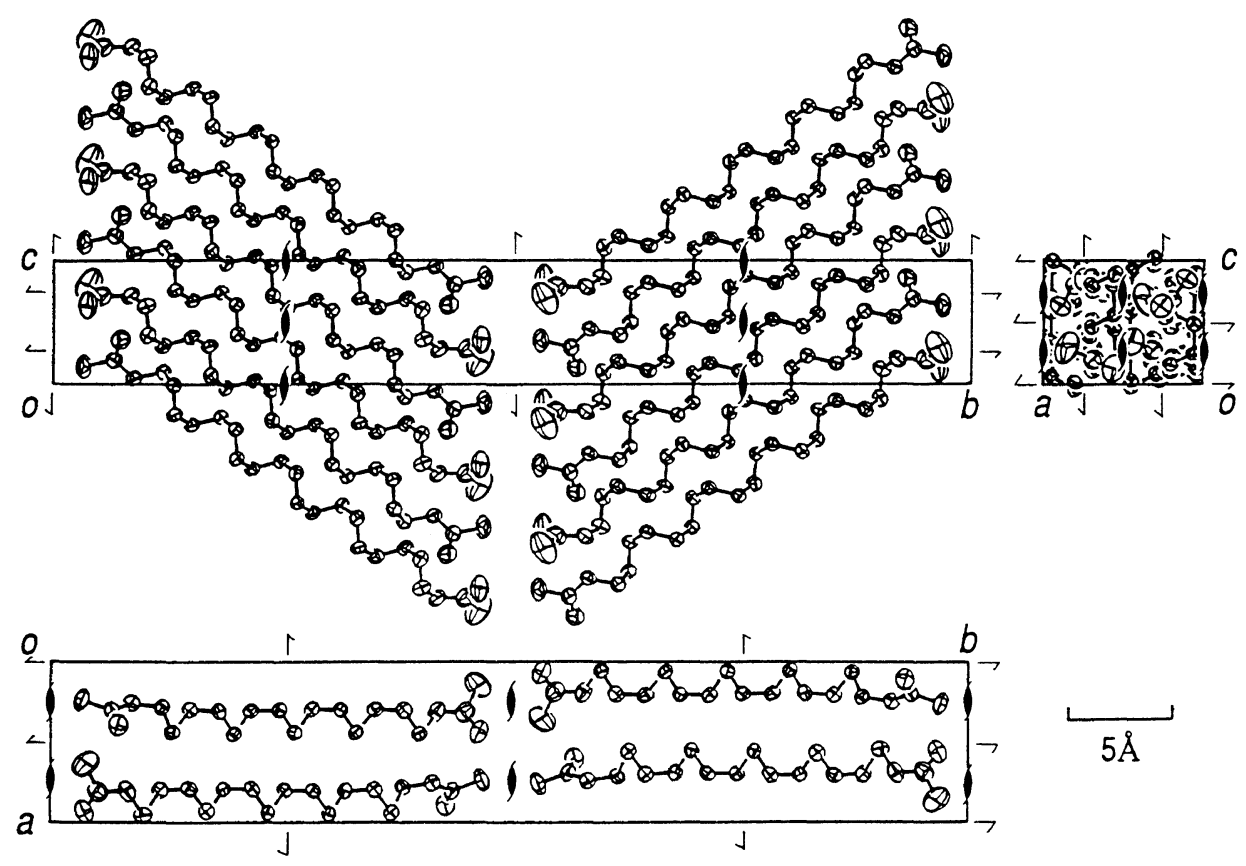

Figure 3. Crystal structure of deca(oxymethylene) diacetate.

Table IV. Dihedral angles in nonaand deca(oxymethylene) diacetates ${ }^{\mathbf{a}}$

\begin{tabular}{|c|c|c|c|c|}
\hline \multirow{2}{*}{$\begin{array}{l}\text { Monomeric } \\
\text { unit }\end{array}$} & \multicolumn{2}{|c|}{9 mer } & \multicolumn{2}{|c|}{$10 \mathrm{mer}$} \\
\hline & $\phi$ & $\phi^{\prime}$ & $\phi$ & $\phi^{\prime}$ \\
\hline 1 & $75.3(12)^{\mathrm{b}}$ & $82.9(10)$ & $96.7(8)^{b}$ & $67.1(8)$ \\
\hline 2 & $71.9(11)$ & $73.3(12)$ & $58.3(8)$ & $63.8(8)$ \\
\hline 3 & $69.6(13)$ & $72.9(13)$ & $66.0(8)$ & $62.1(8)$ \\
\hline 4 & $72.4(12)$ & $67.9(12)$ & $67.0(8)$ & $62.5(8)$ \\
\hline 5 & $74.1(11)$ & $65.4(12)$ & $66.0(8)$ & $64.2(8)$ \\
\hline 6 & $69.9(13)$ & $71.5(13)$ & $66.5(8)$ & $66.1(8)$ \\
\hline 7 & $65.9(13)$ & $73.7(12)$ & $64.1(8)$ & $66.3(8)$ \\
\hline 8 & $65.7(13)$ & $75.5(13)$ & $69.1(8)$ & $61.2(9)$ \\
\hline 9 & $65.4(13)$ & $93.8(10)^{b}$ & $63.5(9)$ & $60.8(9)$ \\
\hline 10 & - & - & $64.2(9)$ & $81.6(10)^{b}$ \\
\hline Average & \multicolumn{2}{|c|}{71.1} & \multicolumn{2}{|c|}{64.4} \\
\hline $\mathrm{O}=\mathrm{C}-\mathrm{O}-\mathrm{C}$ & $-4.0(15)$ & $-5.4(17)$ & $-9.6(13)$ & $0.3(16)$ \\
\hline
\end{tabular}

a Estimated standard deviations in the least significant digits are given in parentheses.

b Values were not included in the calculation of the average dihedral angle.<smiles>COCC1CC1CC1CC1OC</smiles>

inclined slightly $\left(2^{\circ}\right)$ with the lamellar normal (the $a$ axis) (Figure 5). Two of the four molecules adopt the right-handed helix and the other two, the left-handed helix. The average dihedral angle in the acetal linkage is $71.1^{\circ}(c f$. Table IV) which is intermediate between those for the $9 / 5\left(78^{\circ}\right)$ and $2 / 1$ helices $\left(64^{\circ}\right)$. A molecular axis view of the nonamer crystal is shown in Figure $4 b$.

The undecamer also gave plate crystals. The crystal structure of the undecamer was not determined completely because of the large lattice dimensions. However, the partial chain structure obtained by the direct method $(R=26 \%)$ indicated that the acetal backbone of the undecamer consists of the $9 / 5$ helix with an average dihedral angle of $80^{\circ}$. This suggests that the sublattice structure of the undecamer crystal is close to that of the stable trigonal form of poly(oxymethylene). ${ }^{14}$

Studies on the crystal structure of uniform oligo(oxymethylene) diacetates described above reveal that both packing and helix pitch of 
(a) $10 \mathrm{mer}$

(b) 9 mer

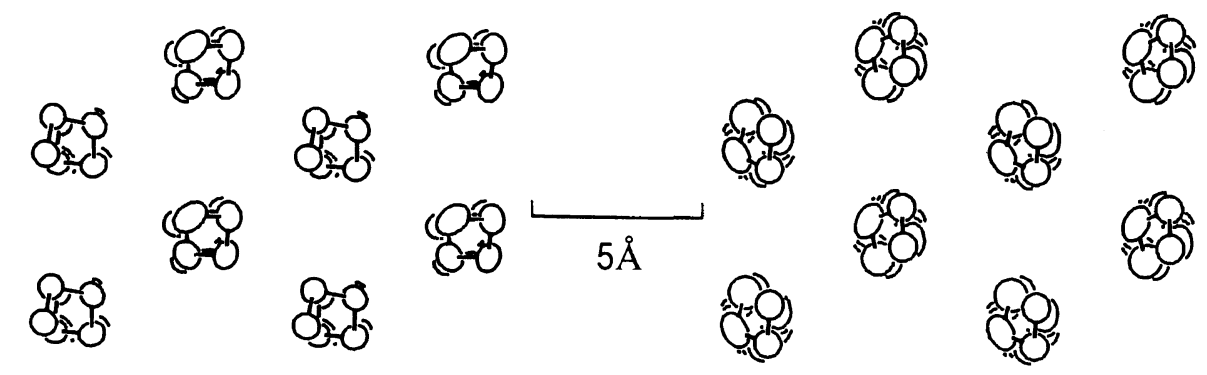

Figure 4. Molecular axis views of deca(oxymethylene) diacetate (a) and nona(oxymethylene) diacetate (b) crystals. The end-groups are omitted for clarity.

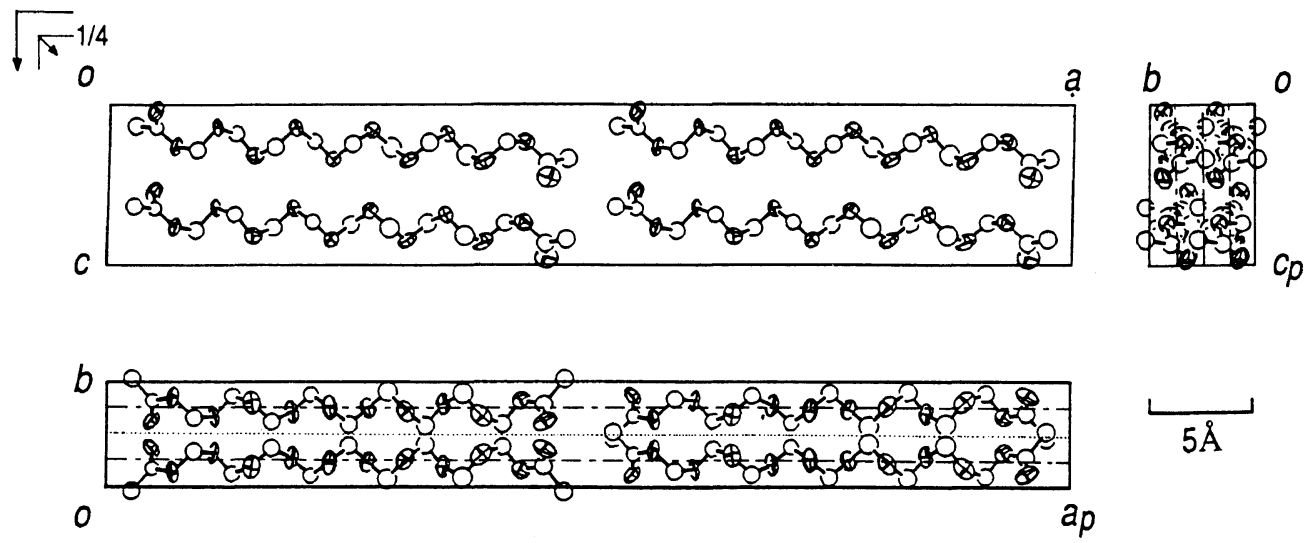

Figure 5. Crystal structure of nona(oxymethylene) diacetate.

the molecules in a unit-cell are dependent on $D P$. The $D P$ dependency is considered to arise from the effects of the acetyl end-groups which are "alien" to the oxymethylene backbones. This situation is in stark contrast to the case of chloral (trichloroacetaldehyde) oligomers $(2 \leq D P \leq 6)$ in which the backbone structure is $4 / 1$ helix irrespective of $D P$ and end-groups. ${ }^{24,25}$

Acknowledgments. The authors are grateful to Mr. A. Tanaka for his helpful discussion. Thanks are also due to Prof. Y. Matsuura (Institute for Protein Research, Osaka University) and Prof. M. Kobayashi (Faculty of Science, Osaka University) for their kind suggestions on X-ray analysis. A part of this work was supported by the Grant-in-Aid for Scientific Research (No. 03453118 and No. 05750786) from the Ministry of Education, Science, and Culture of Japan.

\section{REFERENCES}

1. G. Ungar, J. Stejny, A. Keller, I. Bidd, and M. C. Whiting, Science, 229, 386 (1985).

2. K. S. Lee and G. Wegner, Makromol. Chem., Rapid Commun., 6, 203 (1985).

3. R. E. Jentoft and T. H. Gouw, J. Polym. Sci., B7, 811 (1969).

4. E. Klesper and W. Hartmann, Eur. Polym. J., 14, 77 (1978).

5. Y. Hirata and F. Nakata, J. Chromatogr., 295, 315 (1984).

6. K. Hatada, K. Ute, T. Nishimura, M. Kashiyama, T. Saito, and M. Takeuchi, Polym. Bull., 23, 157 
(1990).

7. K. Ute, N. Miyatake, T. Asada, and K. Hatada, Polym. Bull., 28, 561 (1992).

8. K. Ute, N. Miyatake, Y. Osugi, and K. Hatada, Polym. J., 25, 1153 (1993).

9. H. Staudinger and M. Lüthy, Helv. Chim. Acta, 8, 41 (1925).

10. H. Staudinger, H. Johner, R. Signer, G. Mie, and J. Hengstenberg, Z. Physm. Chem., 126, 425 (1927).

11. H. Staudinger, R. Signer, H. Johner, M. Lüthy, W. Kern, D. Russidis, and O. Schweitzer, Ann. Chem., 474, 145 (1929).

12. H. Tadokoro, S. Yasumoto, S. Murahashi, and I. Nitta, J. Polym. Sci., 44, 266 (1960).

13. G. Carazzolo, J. Polym. Sci., A, 1, 1573 (1963).

14. T. Uchida and H. Tadokoro, J. Polym. Sci., A-2, 5, 63 (1967).

15. G. Carazzolo and M. Mammi, J. Polym. Sci., A, 1, 965 (1963).

16. L. Mortillario, G. Galliazzo, and S. Bessi, Chem. Ind.
(Milan), 46, 139 (1964).

17. M. Iguchi, Polymer, 24, 915 (1983).

18. A. C. North, D. C. Phillips, and F. S. Mathews, Acta Cryst., A24, 351 (1968).

19. G. M. Sheldrick, in "Crystallographic Computing 3," G. M. Sheldrick, C. Kruger, and R. Goddard, Ed., Oxford University Press, London, 1985, p 175.

20. K. Hatada, K. Ute, T. Takahashi, and W. J. Simonsick, Jr., manuscript in preparation.

21. M. Shimomura, M. Iguchi, and M. Kobayashi, Polymer, 31, 1406 (1990).

22. C. F. Hammer, T. A. Koch, and J. F. Whitney, J. Appl. Polym. Sci., 1, 169 (1959).

23. M. Kobayashi, T. Adachi, Y. Matsumoto, H. Morishita, T. Takahashi, K. Ute, and K. Hatada, $J$. Raman Spectrosc., 24, 533 (1993).

24. K. Ute, T. Nishimura, K. Hatada, F. Xi, F. Vass, and O. Vogl, Makromol. Chem., 191, 557 (1990).

25. K. Ute, K. Oka, M. Kashiyama, K. Hatada, F. Xi, and O. Vogl, Makromol. Chem., 192, 35 (1991). 